\title{
THE CLINICAL AND PATHOLOGICAL BACKGROUND OF TWO CASES OF OXALOSIS
}

\author{
BY \\ D. T. D. HUGHES \\ From the Bernhard Baron Institute of Pathology and the London Hospital
}

(RECEIVED FOR PUBLICATION MAY 10, 1959)

The deposition of calcium oxalate crystals in human tissues was first described by Lepoutre (1925), who found these in the kidney of a child aged $4 \frac{1}{2}$ years who also had multiple urethral, ureteric, and bilateral renal calculi. Similar deposits have been described in the kidneys and elsewhere by other authors. Ying Chou and Donohue (1952) suggested the term "oxalosis" to describe the condition in which these crystalline deposits occur, and Scowen, Stansfeld, and Watts (1959) have used it for cases with disseminated extrarenal calcium oxalate deposits. This, though rare, has been identified with greater frequency in recent years. Two further cases are reported here; though they recapitulate many known features of the condition they present some that are new.

\section{Case 1}

P. K. was a 5-week-old boy admitted to hospital because he was fretful and refused his feeds. He was a first child and had weighed $7 \mathrm{lb}$. at birth, which was normal. One week before admission he was weaned from the breast on to dried milk feeds, which he usually took well. During the 24 hours preceding admission he had vomited once and passed a single loose watery stool. His mother had also noticed that he had passed much more urine than usual.

On examination he was pale, listless, and dehydrated,' with deep sighing respirations . and a temperature of $95^{\circ} \mathrm{F}$. There were no other abnormal physical signs.
His blood chemistry was grossly abnormal (Table I), and he was treated with intravenous fluids $(1 / 6$ molar sodium lactate and dextrose saline) and antibiotics (penicillin, streptomycin, and terramycin). The day after admission twitching of the left hand and jerky rolling of the eyes were noticed, and in the course of the next few days he developed generalized convulsions, persisting for three days, which were only partly controlled by paraldehyde. Lumbar puncture yielded clear sterile fluid containing 26 cells per c.mm. (mainly lymphocytes) and $50 \mathrm{mg}$. of protein per $100 \mathrm{ml}$. During the first four days he passed very little urine (maximum measured volume $=105 \mathrm{ml}$.), and on the fourth day both kidneys were palpable. Intravenous therapy was discontinued on that day his urinary output increased thereafter (up to abougi $500 \mathrm{ml}$. a day), and he made an uneventful recovery At this time the serum electrolytes were normal, ando when deprived of water he was able to pass a norma? concentrated urine.

He was readmitted in coma two months later, his parents having noticed that during the preceding night he had again passed excessive amounts of urine and had been " breathing hard." On examination he was dehydrated with sighing acidotic respirations. His blood chemistry was grossly deranged with the serum bicarbonate $10 \mathrm{mEq}$./1. on admission. In spite of intravenous therapy he died two days later, aged 14 weeks, no satisfactory diagnosis having been reached.

Investigations.-The following were carried out : Urine.-Specific gravity was 1011-1016. The urine was acid on admission, becoming alkaline, with a trace of albumin. It was sterile on culture.

TABLE I

BLOOD CHEMISTRY

\begin{tabular}{|c|c|c|c|c|c|c|c|c|c|}
\hline \multicolumn{3}{|l|}{ Date } & Sodium & $\underset{(m E q . / 1 .)}{\text { Potassium }}$ & $\begin{array}{l}\text { Chloride } \\
\text { (mEq./1.) }\end{array}$ & $\begin{array}{c}\text { Bicarbonate } \\
(\mathrm{mEq} . / \mathrm{l} .)\end{array}$ & $\begin{array}{c}\text { Urea } \\
\text { (mg. } / 100 \mathrm{ml} .)\end{array}$ & $\underset{\text { (mg. } / 100 \mathrm{ml} .)}{\text { Calcium }}$ & $\begin{array}{l}\text { Phosphorus } \\
\text { (mg./100 ml.) }\end{array}$ \\
\hline $\begin{array}{l}10 / 6 / 58 \text { (i) } \\
2 \mathrm{hr} \text {. later (ii) } \\
12 / 6 / 58 \text { (iii) } \\
13 / 6 / 58 \text { (iv) } \\
14 / 6 / 58 \text { (v) } \\
16 / 6 / 58 \text { (vi) } \\
10 / 7 / 58 \text { (vii) }\end{array}$ & $\begin{array}{l}\cdots \\
\therefore \\
\therefore \\
\therefore \\
\cdots\end{array}$ & \begin{tabular}{l|}
$\ldots$ \\
$\cdots$ \\
$\cdots$ \\
$\cdots$ \\
$\cdots$
\end{tabular} & $\begin{array}{l}160 \\
160 \\
147 \\
156 \\
140 \\
144 \\
149\end{array}$ & $\begin{array}{l}6 \cdot 3 \\
4 \cdot 4 \\
4 \cdot 8 \\
4 \cdot 8 \\
3 \cdot 4 \\
3 \cdot 8 \\
7 \cdot 9\end{array}$ & $\begin{array}{r}122 \\
116 \\
95 \\
104 \\
90 \\
95 \\
109\end{array}$ & $\begin{array}{r}5 \\
10 \\
6 \\
18 \\
24 \\
27 \\
21\end{array}$ & \begin{tabular}{r|}
63 \\
96 \\
102 \\
130 \\
30
\end{tabular} & $\begin{array}{r}10 \\
8 \cdot 8 \\
8 \cdot 6 \\
10 \cdot 2\end{array}$ & $\begin{array}{l}9 \cdot 7 \\
7 \cdot 7 \\
7 \cdot 9 \\
5 \cdot 3\end{array}$ \\
\hline $\begin{array}{l}\text { Second Admissic } \\
8 / 8 / 58 \text {.(viii) } \\
7.30 \text { a.m.(vii) } \\
11 \text { p.m.(ix) } \\
9 / 8 / 58 \text { (x) }\end{array}$ & $\begin{array}{l}o n \\
\cdots \\
\cdots \\
\cdots\end{array}$ & $\begin{array}{l}\cdots \\
\cdots \\
\cdots \\
.\end{array}$ & $\begin{array}{l}154 \\
154 \\
130\end{array}$ & $\begin{array}{l}7.0 \\
5.4 \\
5.8\end{array}$ & $\begin{array}{r}124 \\
118 \\
88\end{array}$ & $\begin{array}{r}10 \\
6 \\
10\end{array}$ & $\begin{array}{l}87 \\
90\end{array}$ & 9.4 & 8.4 \\
\hline
\end{tabular}


Water Concentration Test.-Specific gravity was 1013 after 12 hours' fluid deprivation and 1015 after 18 hours'.

Maximum urea clearance was $31 \%$ The maximum urea concentration was $14.4 \mathrm{~g}$./litre.

An intravenous pyelogram was normal. Paper chromategraphy of the urine was normal. Rectal swabs grew no pathogens. Over a 17 -hour test period three days after admission he excreted only $2 \mathrm{mg}$. of calcium and $194 \mathrm{mg}$. of phosphorus in a $135 \mathrm{ml}$. volume of urine.

\section{Pathology of Case 1 (P.M. No. 284/1958)}

The kidneys were slightly swollen and oedematous with a normal pattern and uneven yellow streaking of the medullary pyramids. No calculi were found in the urinary tract. The myocardium was pale, but the heart was normal. The lower lobes of both lungs were slightly collapsed. No abnormality was visible in the remainder of the viscera or in the right femur. There was a small recent subdural haemorrhage $(2.5 \mathrm{~cm}$. in diameter $)$ beneath the anterior fontanelle, and a small amount of ante-mortem thrombus in the adjacent sagittal sinus. No visible abnormality in the brain was seen after fixation and hardening in formalin.

The body was that of a pale, well-nourished child with slight pitting oedema of the tissues at the ankles and no evidence of dehydration.

The body weighed $6 \mathrm{~kg}$. (height: $60 \mathrm{~cm}$.), the heart 26 g., spleen 20.7 g., thyroid 1.9 g., testes 2.3 g., suprarenals 4.1 g., pituitary 0.2 g., kidneys (L.) $49.6 \mathrm{~g}$. and (R.) $42.5 \mathrm{~g}$.

Microscopical Examination.-Sections of the pituitary, thymus, thyroid, testis, adrenal, pancreas, liver, spleen, lung, oesophagus, stomach, mesenteric lymph node, large and small intestine, kidneys, and brain were examined, but abnormalities were confined to the last two organs. Unfortunately the bones were not examined because the nature of the disease was not realized at the time of necropsy.

Kidneys.-The renal tubules contained many pale, greenish-yellow doubly refractile crystals, yielding green, yellow, and orange colour patterns in polarized light. These were mostly arranged as broken plates, or, more commonly, as radiating sheaves forming rosettes (Fig. 1). These crystalline deposits distended and distorted the lumina of the tubules, particularly the distal convoluted segment. There were patchy areas of necrosis in the proximal convoluted tubules, and degeneration of the tubular cells in other areas with swelling, disruption, and a rather foamy appearance of their cytoplasm. There was haemorrhage into some of the tubules, particularly proximally. The glomeruli, vessels, and interstitial tissue were normal. There was remarkably little inflammatory response to the crystalline foci, though occasionally they were partly enclosed by giant cells. Only rarely were the tubules actually disrupted and there was virtually no destruction of the normal microscopic renal architecture (Fig. 2).

Brain.-Similar crystals were found unevenly distributed in the brain and cerebral vessels. In the brain substance they were most numerous in the hypothalamus and convolutional white matter, though scanty deposits were present in the cerebellar white matter and in the medulla. The choroid plexus contained none. In some of these sites they had produced no reaction, but a rosette of microglial cells surrounded occasional groups (Fig. 3a). Many of these deposits were paravascular in relation to capillaries, but in the leptomeninges crystals occupied the media of a few small arteries (Fig. 3b). Areas of focal meningitis, with infiltration by polymorphs and large round cells, were found over the floor of the third ventricle and in the depths of a few cerebral sulci, and in the choroid plexus of the left lateral ventricle. These bore no relation to the crystalline deposits, and no bacteria were demonstrated. The solubilities and staining properties of these crystals, together with their chemical composition, are discussed below.

\section{Case 2}

D. R. was the only son of a first-cousin marriage. At the age of 8 he passed a stone of unknown composition per urethram, but had no other urinary troubles. At the age of 11 he developed painful raised red swellings on both shins that persisted for about two weeks, which were regarded as erythema nodosum.

Nearly two years later he developed a cough producing frothy white sputum, after which he became increasingly breathless on exertion. Six months later he was admitted to another hospital on account of progressive oedema of the ankles, legs, and abdomen. He was then found to have signs of constrictive pericarditis with bilateral pleural effusions, which were tapped. Treatment was started with antituberculous drugs (streptomycin and I.N.A.H.) and diuretics (neptal and diamox). One month later, on admission to the London Hospital, he had signs of constrictive pericarditis with pitting oedema to the waist, an enlarged liver, raised jugular venous pressure, and persistent bilateral effusions. An E.C.G. showed changes compatible with pericarditis. Treatment was continued with the same antituberculous drugs, diuretics (diamox), and a restricted salt intake. At this time the blood urea level was $37 \mathrm{mg} . / 100 \mathrm{ml}$. A week after admission treatment was begun with 


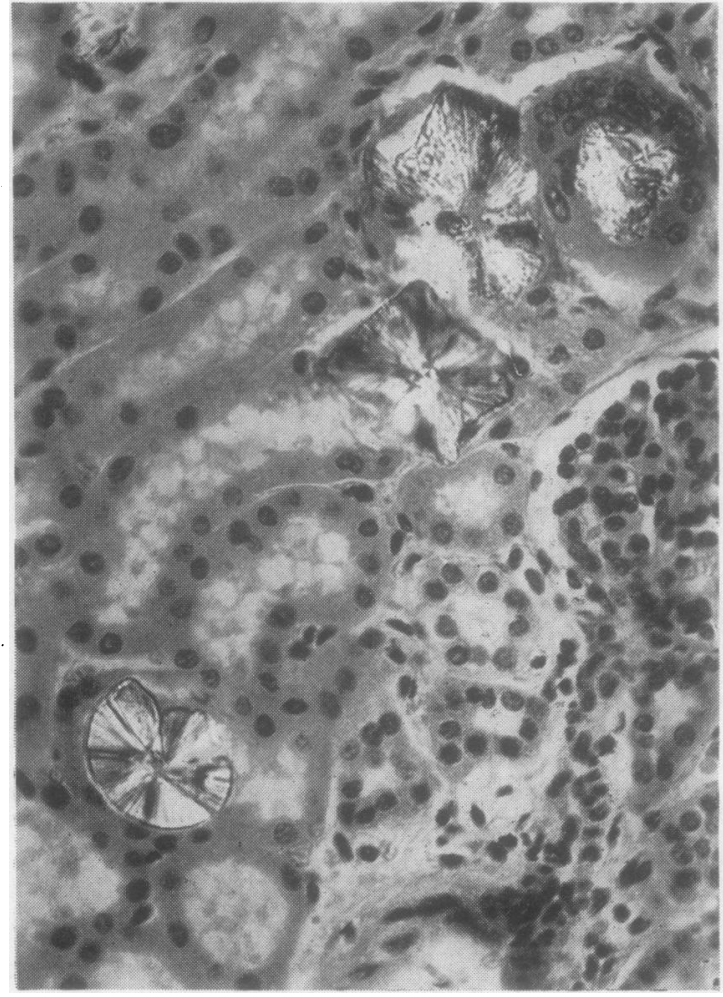

Fig. 1.-Kidney from Case 1. Doubly refractile rosettes of crystals occupy tubules. Haematoxylin and eosin, $\times 350$. Photographed in partly polarized light.

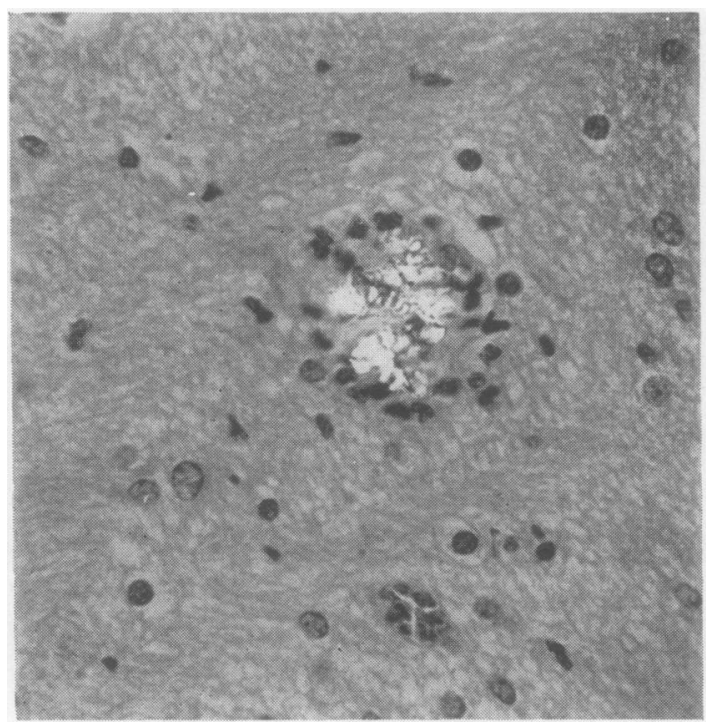

FIG. 3a.-Brain from Case 1. Doubly refractile crystals in hypothalamus enclosed by microglial cells. Haematoxylin and eosin, $\times 240$. Partly polarized light.

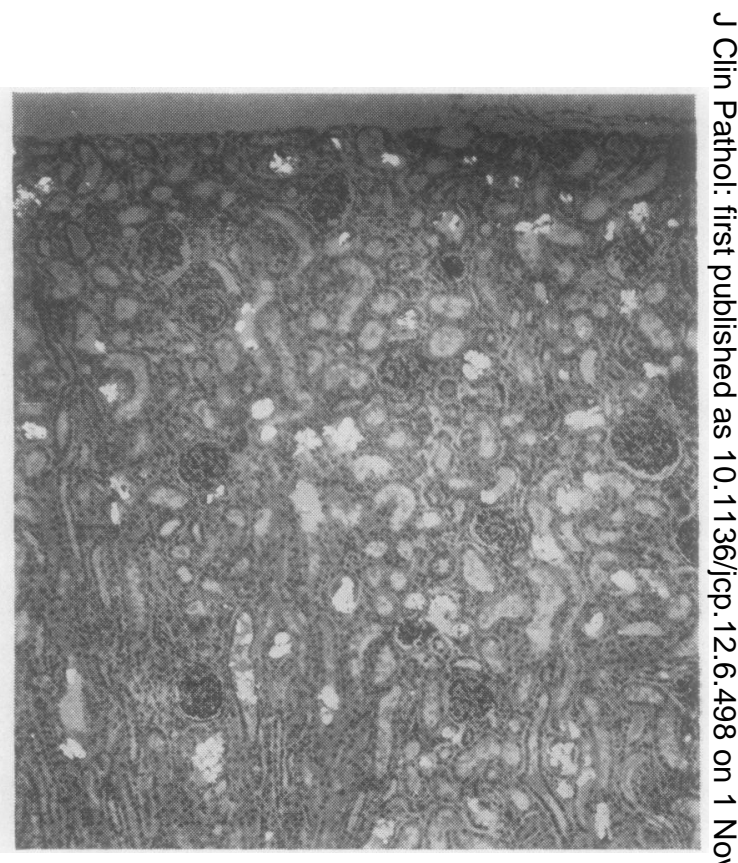

Fig. 2.-Kidney from Case 1. Many doubly refractile crystals in tubules, but none in glomeruli. Normal renal architecture wells preserved. Haematoxylin and eosin, $\times 60$. Partly polarized light.

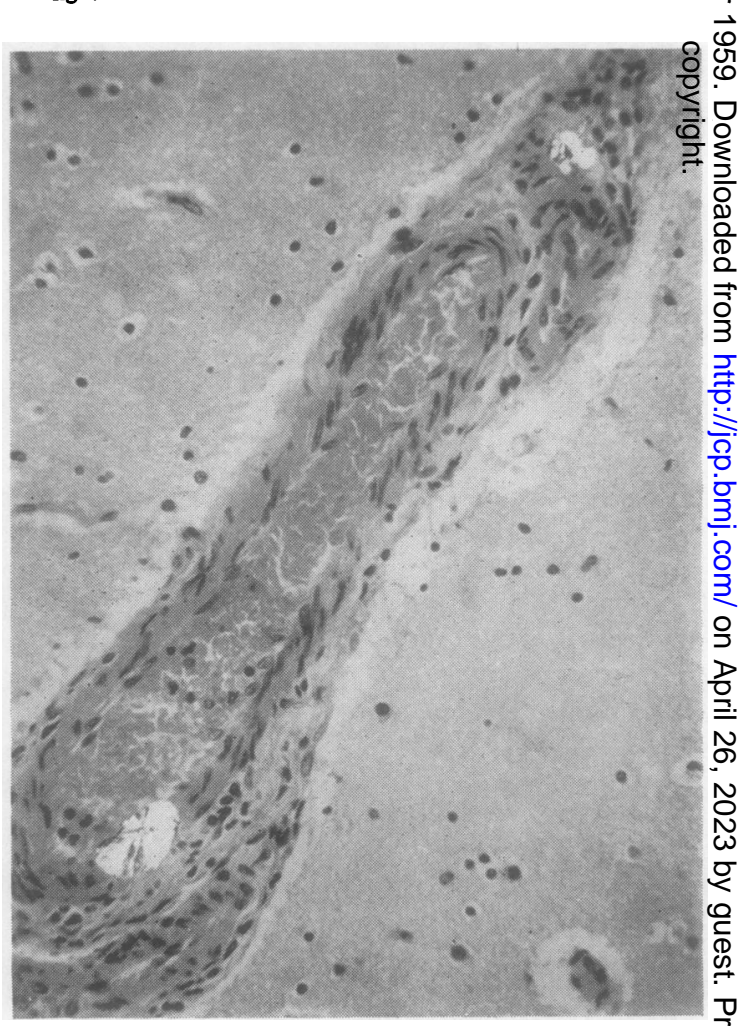

Fig. 3b.-Brain from Case 1. Crystals in the media of small menin-O geal artery, evoking no reaction. Haematoxylin and eosin, $\mathbb{D}$ $\times 400$. Partly polarized light. 


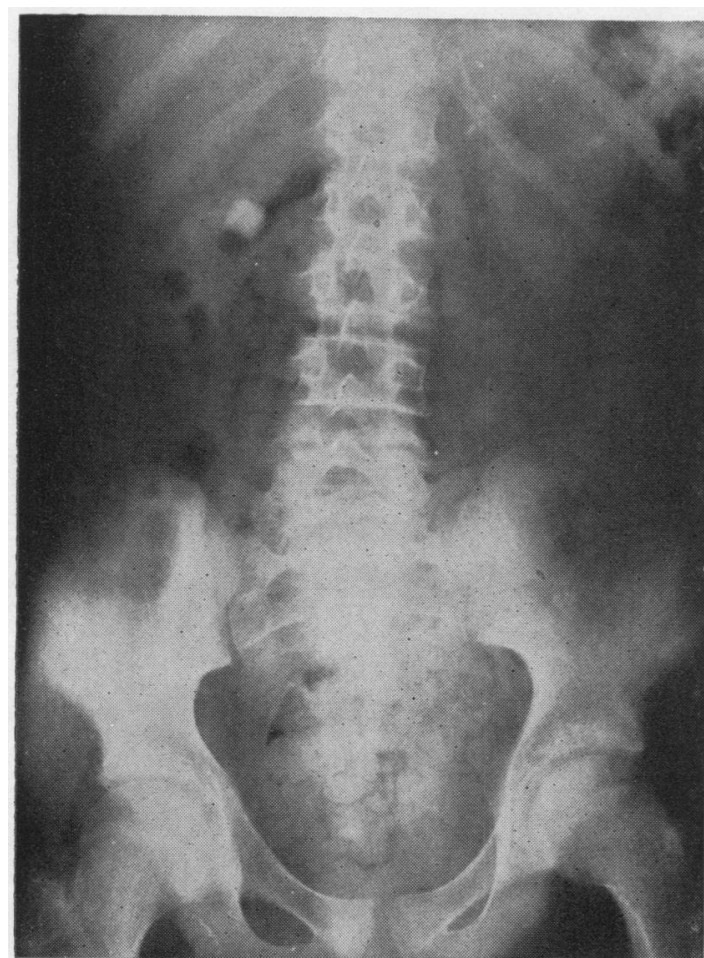

FIG. 4a.-Plain radiograph of abdomen of Case 2, showing bilateral renal calculi.

digoxin and chlorothiazide, which produced a good diuresis and a steady diminution in the oedema. During the next month, however, he became febrile and developed a right-sided pleural friction rub. The E.S.R. rose, and a chest radiograph showed an area of consolidation at the apex of the right lower lobe. A tuberculous "flare-up" was suspected and P.A.S. started. Ten weeks after admission the blood urea level was first raised ( $84 \mathrm{mg} . \%$ ), and renal function was further investigated. A straight radiograph of the abdomen showed bilateral renal calculi (Fig. 4a) but no obvious nephrocalcinosis. (A post-mortem radiograph, however, showed fine radial streaking (Fig. 4b).) Meanwhile he slowly deteriorated and the blood urea rose steadily, until six months after admission it reached $260 \mathrm{mg}$. \%. In an attempt to relieve any possible obstruction right ureterolithotomy was performed a few days later, and a calcium oxalate stone was removed from the right pelvi-ureteric junction. A renal biopsy was also taken. Post-operatively his urinary output declined, his blood pressure fell, and he died 54 hours later.

Investigations. -The following investigations were carried out :

Blood.-Haemoglobin was $96 \%$, falling to $56 \%$. A white cell count gave 5-11,000 with regularly 70$80 \%$ polymorphs. The E.S.R. was $7-45 \mathrm{~mm}$./hour. The serum calcium level was $11.7,10.1,11.4,6.9$, and

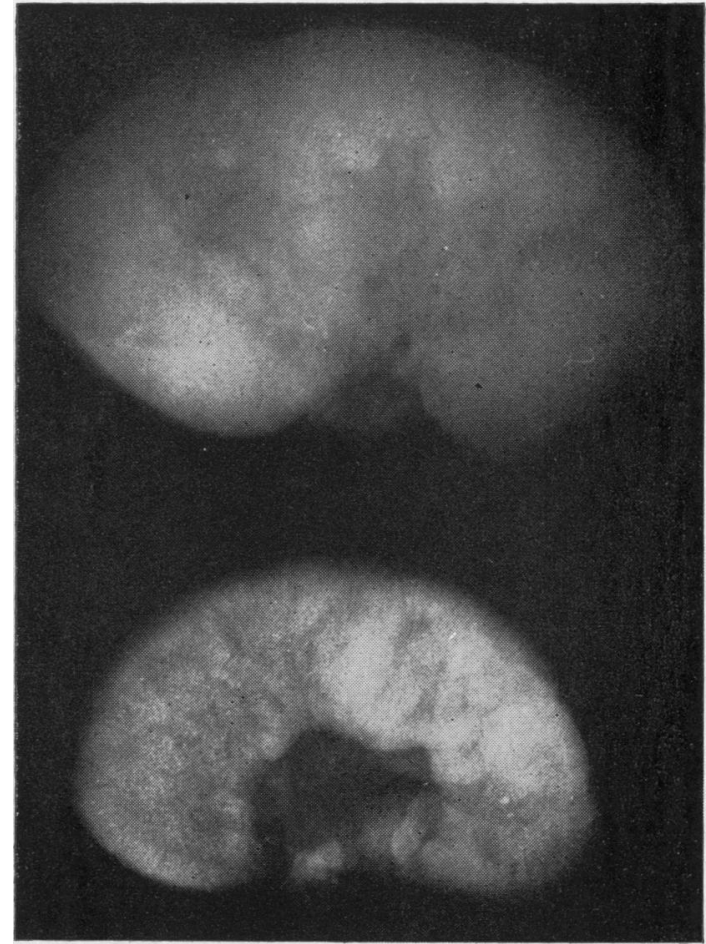

FIG. 4b.-Radiograph of kidney from Case 2 (below) removed at necropsy compared with control.

$7 \mathrm{mg} . \%$, and the serum phosphorus level 6.1, 5.2, 5.3, 7.4 , and $7.5 \mathrm{mg} . \%$, and alkaline phosphatase $8,14,25$, and 27 King-Armstrong units. (The last two estimations in each case were carried out within three weeks of death.) Other serum electrolytes were normal, except for some variation in potassium (3.8-7.5 $\mathrm{mEq}$./1.) due to the administration of chlorothiazide with potassium supplements.

Blood Urea.-On February 7 the level was 20 mg. \% ; between March 2 and April 2, 33-37 mg. \%; on May $15,84 \mathrm{mg} . \%$, after which it rose steadily to reach $260 \mathrm{mg}$. \% on September 4 (13 days before death).

Liver Function.-Tests were repeatedly normal, except for a single raised bilirubin value of $1.3 \mathrm{mg} . \%$ at the time when he had the fever, friction rub, and raised E.S.R. Plasma proteins were $5.6 \mathrm{~g}$. \% rising to 7.5 g. \% (albumin 5.1, globulin 2.3).

Urine.-Specific gravity never rose above 1012 , except on one occasion after a course of chlorothiazide. Urine was sterile on culture, containing a trace of albumin and a moderate number of white blood corpuscles. Paper chromatography and 24hour cystine excretion were normal. Calcium-balance studies were carried out a month before death, but their results must be interpreted with caution as the boy was ill, vomiting, and in renal failure by then. 
However, with an intake of 543, 639, and $612 \mathrm{mg}$. of calcium on three successive days the urinary excretion was only 18,37 , and $21 \mathrm{mg}$. of calcium respectively. A single specimen of urine $(175 \mathrm{ml}$.), which was virtually his total output in his last 24 hours, contained $23 \mathrm{mg}$. anhydrous oxalic acid per $100 \mathrm{ml}$.

No tubercle bacilli were identified or cultured from sputum, pleural aspirate, or urine.

\section{Pathology of Case 2 (P.M. No. 313/1958)}

The capsule was slightly adherent to the smooth surface of the kidneys, which were of normal size for the boy's age. Numerous fine yellow gritty flecks were seen on the outer surface and throughout the cut surfaces, especially in the cortex (Fig. 5). The pattern was not obviously blurred, and the calices, pelves, and ureters were not dilated. No calculi were found in the urinary tract. There was a sutured incision in the lower pole of the right kidney. The parietal pericardium showed a slight fibrous thickening $(0.1$ to $0.2 \mathrm{~cm}$.), producing stenosis (to $1.5 \mathrm{~cm}$. in circumference) of the superior vena cava at its junction with the right atrium. The pericardial sac was obliterated by fibrous adhesions, separable posteriorly but not anteriorly. No evidence of tuberculosis was found. There was no visible abnormality of the heart. Slight fibrous thickening of the visceral pleura was visible with delicate adhesions over the postero-inferior surfaces of the right lower lobe, in which there was a recent infarct in the upper posterior segment. Patchy congestion was seen throughout both lower lobes. There was no evidence of active or obsolete tuberculosis, apart from focal calcification of a lymph node eroding the trachea on the right, $2 \mathrm{~cm}$. above the carina. About 12 superficial ulcers were found in the rectal mucosa, but the remainder of the alimentary tract was normal. The right femur was slightly

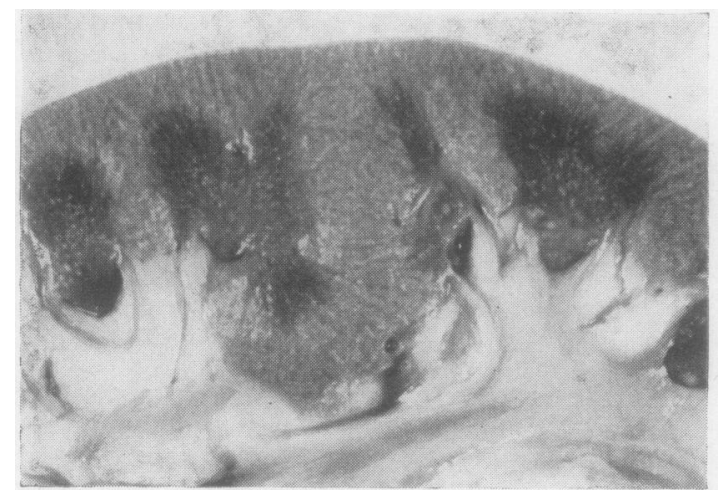

Fig. 5.-Photograph of part of cut surface of kidney from Case 2 to illustrate finely granular radiate yellow streaking (cf. Fig. 4b).

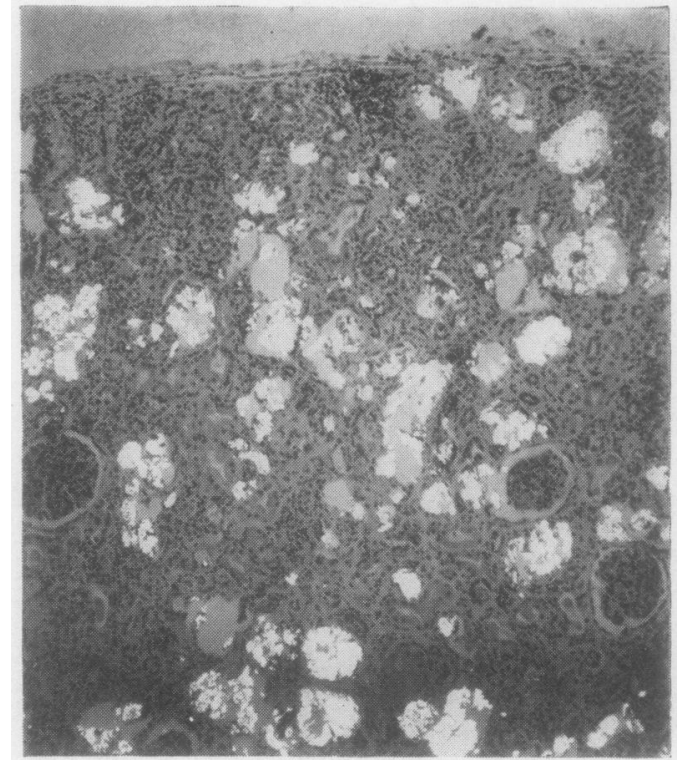

FIG. 6.-Kidney from Case 2. Doubly refractile crystals in tubules and interstitial tissue, but glomeruli again spared. Considerable disruption of normal renal pattern. Haematoxylin and eosin, $\times 60$. Partly polarized light.

bowed, with normal dense cortical bone (up te $0.6 \mathrm{~cm}$. thick) and reddish-brown marrow in the upper two-thirds of the shaft and head and dense cancellous bone at its extremities and in the vertebral bodies. Colloid was abundant in the nodular, slightly enlarged thyroid. Three unenlarged parathyroid glands were found at normal sites. The nervous system was normal.

The body was that of a poorly nourished, slightly built boy, with brownish pigmentation of the external genitalia and extremities and a recent sutured incision in the right loin.

The body weighed $40.2 \mathrm{~kg}$. (height: $163 \mathrm{~cm}$.), the heart $269 \mathrm{~g}$., spleen $134 \mathrm{~g}$. , thyroid $17.8 \mathrm{~g}$., testes 18.1 g., suprarenals 11.4 g., pituitary $0.4 \mathrm{~g}$., each kidney $92 \mathrm{~g}$.

Microscopical Examination.-In this case similar doubly refractile crystals were found rather more widely distributed throughout the body.

Kidneys.-The renal architecture was distorted (Fig. 6), the tubules distended and disrupted by crystalline deposits which were also found lying in rosettes only partly surrounded by tubular cells, and in some instances even in the interstitial tissue. There was widespread degeneration of the tubular epithelium which was markedly thinned in some of the more dilated tubules, and haemorrhage into the tubules, some of which contained granular 
casts. Although there seemed to be little reaction to the crystals there were scattered foci of fibrosis and round cell infiltration, particularly in the cortex. The glomeruli and vessels again contained no crystals and appeared normal.

Bones. - Similar crystalline deposits also occurred in vertebrae, femur, and sternum. In the first these lay mainly in lacunae at the osteochondral junction (Fig. 8a) where they were often related to active foci of osteoblasts. A few were found in the bony trabeculae, and this was their site in the sternum. They had produced no reaction and no obvious disturbance of bone growth. None were found in the marrow at any of these sites. The thyroid gland contained occasional crystals, both in the follicles and interstitial tissue, whilst the testis contained crystals within the lumina of some of the seminiferous tubules (Fig. 9). In none of these sites did they evoke any cellular reaction. No other endocrine glands contained crystals. The three parathyroids were normal. There was a mass of similar crystals in the paratracheal lymph node which was eroding the trachea, particularly concentrated around necrotic calcified material (Fig. 10). A carinal and mediastinal lymph gland contained no crystals. Occasional doubly refractile crystals were seen within some of the cardiac muscle fibres, whilst there were scanty deposits in the fibrotic pericardium. The latter contained a few foci of lymphocytes. Sections of the lower lobe of the right lung showed oedema with an area of haemorrhagic infarction and foci of early purulent bronchopneumonia. No tubercle bacilli, giant cells, epithelioid cells, or caseation were found in the lungs and pericardium. No crystals were found in sections of liver, spleen, pancreas, or rectum. Unfortunately the brain was not examined.

\section{Identification of Crystalline Material}

Solubilities and Staining Reactions of the Crystals-In each case the crystalline deposits were observed in paraffin sections prepared in the routine way after fixation with $4 \%$ saline formaldehyde. They were insoluble in dilute and glacial acetic acid, saturated ammonia, and $10 \mathrm{~N}$ potassium hydroxide, but were readily soluble in dilute mineral acids, e.g., normal hydrochloric or sulphuric. They did not stain by haematoxylin, eosin, methyl or cresyl violet, and Schmorl's reagent. Both Alcian blue and Schiff's reagent (containing dilute hydrochloric acid) dissolved the crystals but stained amorphous material at the same sites, possibly indicating some organic crust

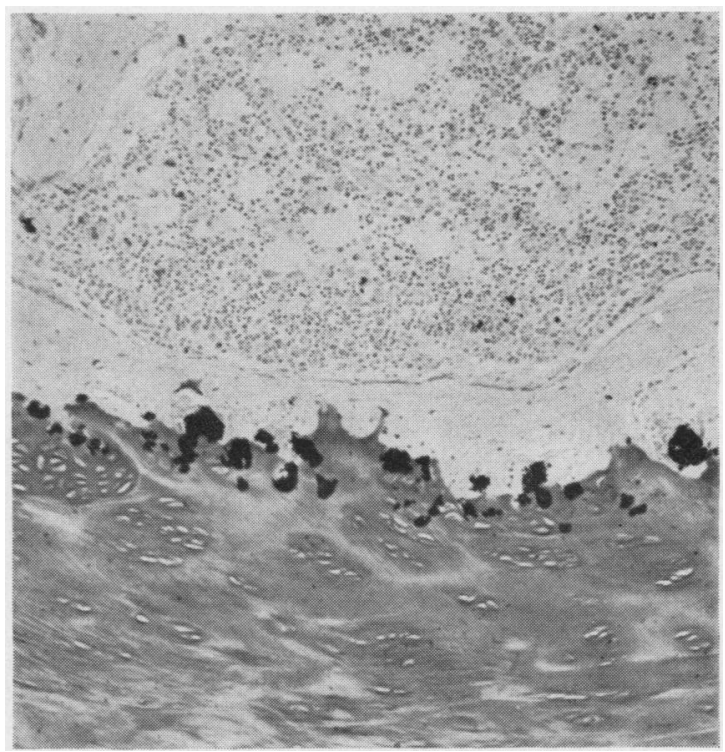

Fig. 7.-Vertebra from Case 2. Deposits stained black by von Kossa method, $\times 77$.

or matrix associated with them. Sections containing crystals decolorized dilute warm solutions of potassium permanganate unlike control preparations, and after exposure to acid permanganate the crystals disappeared. The crystals were stained black by the von Kossa method (Fig. 7). All these properties lead to the conclusion that the crystals are calcium oxalate.

Chemical Extraction of Kidneys.-The oxalic acid and calcium contents of the kidneys of the two cases were estimated. The procedure for estimating oxalic acid was somewhat complex, being a modification of that devised by Andrews and Viser (1951) to estimate the oxalic acid content of food. It depends on successive extractions of the test material with acid and ether.

These authors studied the effect of altering the concentration of hydrochloric acid and the time of extraction in the first stage, and the acidity and time of ether extraction in the second. They concluded that extraction for five hours with a concentration of $\mathrm{HCl}$ between 3-7 N, followed by extraction with ether for 15 to 25 hours, was the most effective method.

Method.-Whole kidneys were stripped of their capsules and pelvic fat and minced to a fine powder, which was dried to constant weight. Aliquots of approximately 2 to $5 \mathrm{~g}$. were then placed in a coarse sintered glass crucible and extracted for five hours with $6 \mathrm{~N} \mathrm{HCl}$ in a Soxhlet extractor. This extract, 


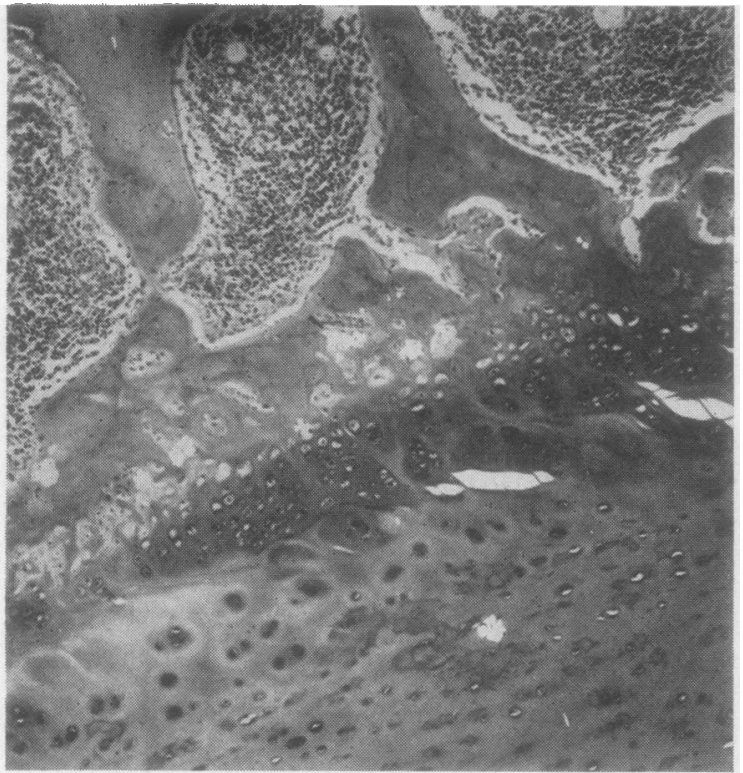

Fig. 8a.-Vertebra from Case 2. Deposits at osteochondral junction and in trabecular bone. Haematoxylin and eosin, $\times 66$. Partly polarized light.

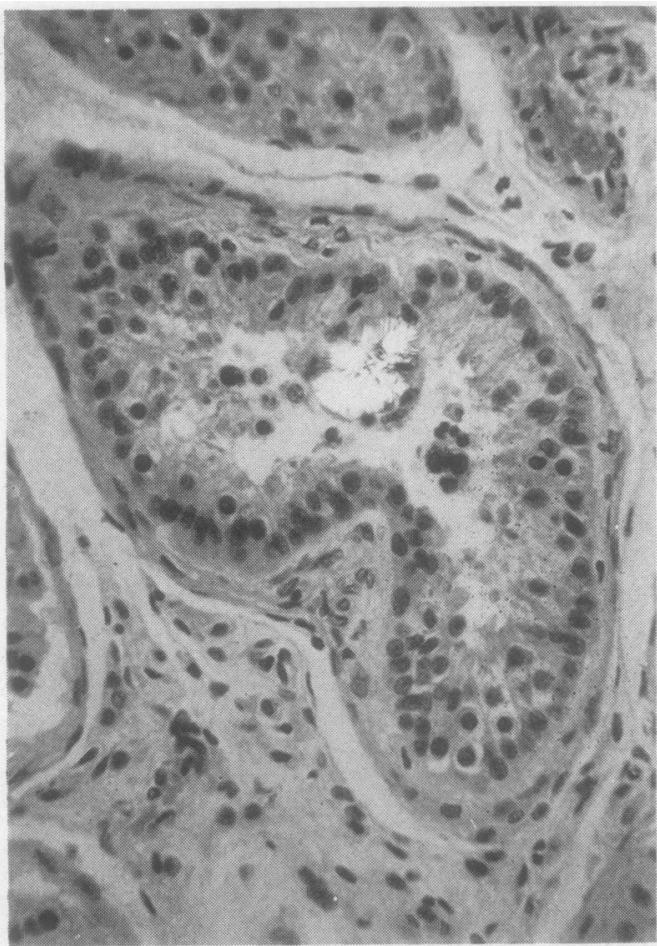

Fig. 9.-Testis from Case 2. Rosette-shaped crystalline mass in seminiferous tubule. Haematoxylin and eosin, $\times 270$. Partly polarized light.

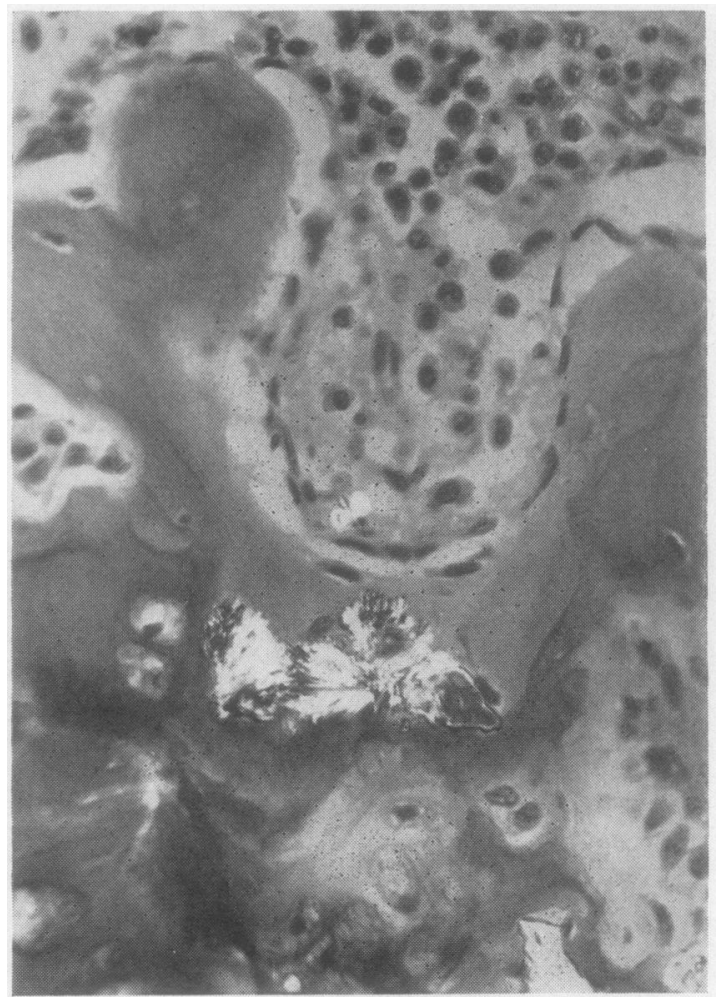

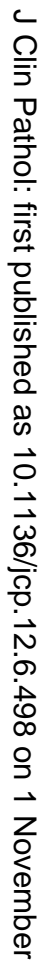

FIG. 8b.-High magnification $(\times 370)$ of Fig. 8a, showing crystals im $\overrightarrow{0}$ trabecular bone.

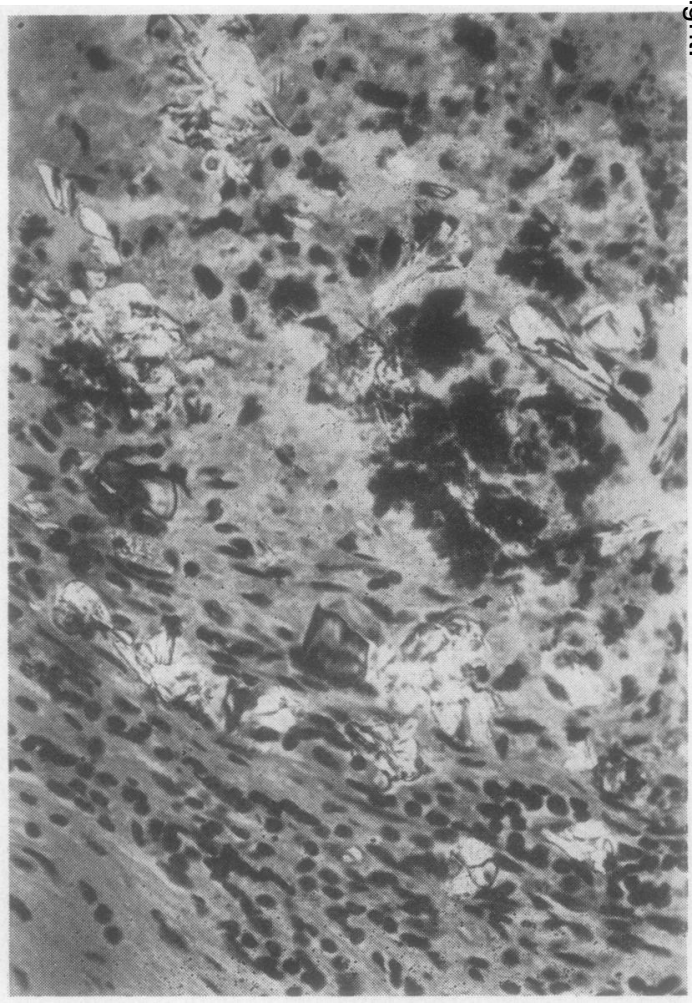

Fig. 10.-Paratracheal lymph gland from Case 2. Many doubly refractile crystals close to deeply staining necrotic calcified material. Haematoxylin and eosin, $\times 330$. Partly polarized light. 
together with washings from the apparatus, was allowed to cool and then filtered through a Whatman's 42 (acid-resistant) filter paper. Aliquots, each of $30 \mathrm{ml}$., of this filtrate were then extracted with ether (using $200 \mathrm{ml}$. ether and $25 \mathrm{ml}$. of distilled water) for 20 hours in a liquid-liquid extractor. The ether was distilled off and the resulting aqueous solution was adjusted to $p \mathrm{H} 5.2$ as recommended by Archer, Dormer, Scowen, and Watts (1957a) and the volume made up to $80 \mathrm{ml}$., which was filtered and decanted into two $50 \mathrm{ml}$. centrifuge tubes.

Excess $\mathrm{CaCl}_{2}$ was added to precipitate any oxalic acid as calcium oxalate, and the tubes left standing for 16 hours. At the end of this time a grey precipitate formed. The tubes were spun, the supernatant fluid removed, and the precipitate washed with falling dilutions of ammonia (10N, N, and finally $0.35 \mathrm{~N})$. The resulting white precipitate was dissolved in $\mathrm{N}_{2} \mathrm{SO}_{4}$ and titrated with standard permanganate at $60^{\circ}$. The results were expressed as oxalic acid dihydrate $(\mathrm{COOH})_{2} 2 \mathrm{H}_{2} \mathrm{O}$.

Calcium was estimated by ashing the dry kidney extracts to calcium carbonate, which was then dissolved in acid. The solution was rendered alkaline with ammonia and excess ammonium oxalate added. The resulting precipitate was washed and titrated as above.

Results.-The results are shown in Table II. A few points arise. First, a small amount of N/100 permanganate was needed to produce lasting pink coloration of solutions of $\mathrm{N}_{2} \mathrm{SO}_{4}$. This was taken as a blank reading. After final washing of the controls there was no appreciable precipitate left, though the solution was faintly cloudy. This cleared on the addition of acid and a minute amount of $\mathrm{N} / 100 \mathrm{KMnO}_{4}(0.01-0.02 \mathrm{ml}$.) above the blank reading was needed to give a lasting pink colour. Even taking this into account, the values were less than $0.1 \mathrm{mg}$. oxalic acid per gramme dry weight of kidneys for all three controls. On the addition of $50 \mathrm{mg}$. of oxalic acid to one control

TABLE II

CALCIUM AND OXALIC ACID CONTENTS OF KIDNEYS

\begin{tabular}{|c|c|c|c|}
\hline Kidney & $\begin{array}{c}\text { Dry } \\
\text { Weight } \\
\text { (g.) }\end{array}$ & $\begin{array}{c}\text { Oxalic Acid } \\
\left((\mathrm{COOH})_{2} \mathrm{H}_{2} \mathrm{O}\right) \\
(\mathrm{mg} / \mathrm{g} . \\
\text { Dry Weight })\end{array}$ & $\begin{array}{c}\text { Calcium } \\
\text { (mg./g. } \\
\text { Dry Weight) }\end{array}$ \\
\hline 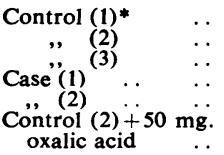 & $\begin{array}{r}12.72 \\
13.85 \\
6.28 \\
5.13 \\
13.45\end{array}$ & $\begin{array}{l}\text { Nil† } \\
\text { Nil } \\
1 \ddot{8} \cdot 9 \\
77 \cdot 2 \\
49 \cdot 5\end{array}$ & $\begin{array}{l}0.13 \\
0.05 \\
12 \cdot 5 \\
57 \cdot 0\end{array}$ \\
\hline
\end{tabular}

* Controls were: (1) man of 57 with mesenteric thrombosis; (2) man of 52 with bronchial carcinoma; (3) boy of 6 months with gastro-enteritis.

The control kidneys, which approximated in dry weight to those of the two cases, were removed at necropsy and immediately dried to constant weight. Sections of each were examined and contained no crystals.

+ See text. kidney, $98.2 \%$ recovery was obtained. This is not a perfect control, but seemed the most practical in the circumstances. The results revealed large amounts of calcium and oxalic acid in the two affected kidneys, the total oxalic acid content of the kidney of Case 2 being over $1 \mathrm{~g}$.

X-ray Diffraction Studies.-The crystalline deposits in kidneys from Cases 1 and 2 were identified as calcium oxalate monohydrate by $x$-ray diffraction studies kindly carried out by Dr. R. J. R. Cureton, of St. Bartholomew's Hospital.

\section{Discussion}

Review of Cases Already Reported.-Although this paper primarily reports the findings at necropsy in two cases of oxalosis, the nature of this condition and its relation to oxalate metabolism will be considered.

Calcium oxalate crystals were first identified in the urine by Donne in 1839 . This led, during the next 50 years, to the concept of an "oxalic acid diathesis," which consisted of the association of large numbers of such crystals in the urine of patients with various dyspeptic, nervous, and rheumatic symptoms (Bird, 1842; Begbie, 1849), and received much attention from French workers, who even compared oxaluria with gout, coining the phrase "goutte oxalique" (Loeper, 1933) which, besides its rheumatic manifestations, could present with anaemia, migraine, and even intestinal "crises" similar to those of tabes. Raised levels of oxalic acid in the blood, urine, and cerebrospinal fluid (Rodillon, 1933) were described, but the methods of estimating oxalate were by no means perfect, and many of the results were conflicting. After about 1900 the "oxalic acid diathesis" fell into disrepute in English- and German-speaking countries, although still described in the medical textbooks (Osler, 1935), and interest in it has been renewed only in the last decade. This has been due to the development of more satisfactory methods of determining oxalates (Barrett, 1942; Archer et al., $1957 b)$, and to the description by various authors (Zollinger and Rosenmund, 1952 ; Burke, Baggenstoss, Owen, Power, and Lohr, 1955, etc.) of deposits of calcium oxalate crystals at various sites in the body, particularly the renal tubules. In the last 10 years over 20 cases of oxalosis have been reported. In all these calcium oxalate crystals were found in the renal tubules, also at other sites in some. Some of these cases are compared and contrasted in tables by Dunn (1955) and by Archer et al. (1958a). Haematuria, with or without the passage of calculi, was the principal 
clinical feature. Nephrocalcinosis, nephrolithiasis, or both, formed a constant radiological finding.

Most patients died in childhood or early adult life, the ages of death ranging from 5 months to 22 years. Four cases dying in middle life, the eldest aged 57, have been reported, however (Zollinger and Rosenmund, 1952; Lund and Reske-Nielsen, 1956). Death in all cases was due to renal failure, with or without complicating urinary infection. In many cases the diagnosis was only reached in retrospect at necropsy, but in four cases (Aponte and Fetter, 1954 ; Godwin et al., 1958 ; Scowen et al., 1959) urinary oxalate estimations in vivo had previously established an increased excretion of oxalic acid (hyperoxaluria). Archer et al. (1957a, 1958a) have suggested that the triad of hyperoxaluria, nephrocalcinosis or nephrolithiasis, and oxalosis forms a single syndrome ("primary hyperoxaluria"), which may be an inborn error of metabolism, comparable with cystinuria and xanthinuria and perhaps hereditary. In support of this hypothesis, Aponte and Fetter (1954) reported cases in twins and in a third sibling, whilst Newns and Black (1953) suspected the condition in the brother of their case ; also Edwards (1957) has reported crystalline deposits of calcium oxalate in the renal parenchyma and myocardium of two brothers dying of renal failure. The father of Dunn's case had passed a single calculus of unknown composition. Myers (1957) mentions three cases of suspected oxaluria occurring in twin girls and their sibling brother. Archer et al. (1958b), however, carried out urinary oxalate determinations on members of three families containing cases of hyperoxaluria, but failed to find an increased oxalate excretion in any of the related subjects.

Since, however, each component of the triad can occur independently the finding of a single one may be insufficient to establish the diagnosis. As pointed out by Archer et al. (1958a), an increased oxalate excretion is the most reliable criterion. But hyperoxaluria has been described in other conditions. Thus Baldwin (1900) described it in dogs following prolonged feeding with excessive amounts of glucose, whilst Loeper (1933) and others (Jeghers and Murphy, 1945) claim that it is often associated with diabetes. Hyperoxaluria has also been reported following the administration of such compounds as gelatin, glycerin, creatine, and purines (Barber and Gallimore, 1940), and ascorbic acid (Lamden and Chrystowski, 1953). It also occurs in ethylene glycol poisoning (vide infra).
Although most cases of hyperoxaluria have calcium oxalate stones (usually pure) in the renal tract the reverse is far from true. Calcium oxalate, either pure or mixed with phosphate, carbonate, or urate, is a common constituent of urinary calculi. The percentage of urinary calculi reported to contain oxalate varies from author to author and from country to country. In America over $30 \%$ of stones contain oxalate (Jeghers and Murphy, 1945), whilst in central Europe between the wars it was reputed to be $65-90 \%$. As hyperoxaluria often presents in childhood, the observation by Myers that 12 out of 59 urinary calculi (approximately 20\%) analysed at The Hospital for Sick Children, Great Ormond Street, between 1936 and 1956 contained calcium oxalate is perhaps more pertinent. Even oxalate calculi in children, however, can exist independently of hyperoxaluria as was shown when Archer et al. estimated the urinary oxalate excretion of the three siblings and other members of the family mentioned by Myers, all of whom were found to have a normal oxalate excretion. Recently Hodgkinson (1958) has measured the 24-hour urinary excretion of oxalic acid in 19 subjects with pure or mixed calcium oxalate stones and found it to be raised in a single instance only. The pathogenesis of calcium oxalate calculi is obviously complex, and the excretion of excessive amounts of oxalic acid is but one factor. Further, the tendency to form such stones may be hereditary. Gram (1932) published the pedigree of his own family, a number of whom (15 in five generations, all male) had suffered from renal calculi. These had been analysed and found to contain calcium oxalate in five cases. From his data he suggested that the disposition to form oxalate urinary calculi might be inherited as a single dominant character, only clearly showing itself in males (possibly due to such factors as urinary stasis behind an enlarged prostate). Only one of his cases had symptoms before the age of 30 , however, and no urinary oxalate estimations were carried out. It cannot therefore be claimed that this family had hyperoxaluria, although a strong case is presented for a hereditary tendency towards oxalate stone formation. There are, of course, many known causes of nephrocalcinosis besides primary hyperoxaluria.

Oxalosis can also occur as a separate entity. It was found incidentally by Laas (1941), who described calcium oxalate crystals in the renal tubules of a man of 25 who died of peritonitis after a gunshot wound. Glynn (1940) found doubly refractile crystals arranged in a rosette 
pattern in the middle cerebral artery of a woman ef 61 dying from rupture of an aneurysm of the left middle cerebral artery. From their solubilities and staining reactions he concluded that these were calcium oxalate. Doubly refractile calcium oxalate crystals have also been described in the thyroid gland by Richter and McCarty (1954) and others. The significance of these sporadic deposits is uncertain.

The Present Cases.-Although the output of urinary oxalate was not estimated in the two personal cases described in this paper, the condition of oxalosis was established by histological examination and the diagnosis of primary hyperoxaluria appears warranted.

Case 1.-This is the youngest fatal case so far reported. The clinical picture here of extreme acidosis and severe dehydration provided a unique clinical problem in a different category from the " hyperchloraemic acidosis" described by Lightwood (1935) or by Butler, Wilson, and Farber (1936). These last authors described four fatal cases in children under the age of 1 , presenting as persistent dehydration and acidosis in the absence of vomiting, diarrhoea, or inadequate fluid intake. These infants had a raised plasma chloride (up to $132 \mathrm{mEq}$./1.) and reduced bicarbonate (down to $6 \mathrm{mEq}$./1.). At necropsy calcium was deposited in the walls of the renal tubules, but no doubly refractile crystals were found. In Case 1 , however, once the initial dehydration was overcome the low bicarbonate persisted with a normal chloride level (Table I). Another interesting point is the delayed diuresis and the persistent elevation of the blood urea after the acidosis had been corrected.

The cause of the convulsions is uncertain, though the two other cases reported in children under 1 year (Mulloy and Knutti, 1951 ; Katzuni and Sandbank, 1959) also suffered from them. It has been suggested (Jeghers and Murphy, 1945) that such convulsions could be due to hypocalcaemia, and the serum calcium was, in fact, at one time reduced to less than $10 \mathrm{mg}$. per $100 \mathrm{ml}$. They were more likely due to the presence of an increased concentration of oxalate in the central nervous system. In the present case and in that reported by Katzuni and Sandbank, calcium oxalate crystals were found in the brain, and the cerebrospinal fluid in the case reported by Scowen et al. (1959) contained appreciable amounts of oxalate. That oxalates can damage the brain and cause convulsions is also suggested by the findings in cases of ethylene glycol poisoning. Pons and Custer (1946) described 18 fatal cases, most of which died within 24 to 48 hours after convulsions and coma. At necropsy calcium oxalate crystals were found in the renal tubules, brain substance, and cerebral blood vessels. These cases also showed changes in the brain suggestive of sterile meningitis or encephalitis. In fact the microscopic findings in the brain closely resembled our findings.

The changes in the kidneys are evidently those of an uncomplicated oxalosis, the crystals being confined to the tubules and the normal renal architecture being well preserved. Most of the cases previously reported have been in older subjects, many of whom showed additional renal changes secondary to prolonged pyelonephritis. In fact the changes in Case 1 are similar to those found in rabbits with induced "oxalate nephritis."

Dunn, Haworth, and Jones (1924a) studied the effect of administering soluble oxalate salts to rabbits, and found that when moderate doses were given for prolonged periods (four to 25 days) lesions in the proximal renal tubules were found at necropsy. These included a foamy appearance in the epithelial cells and desquamation of cells into the lumina, which were packed with calcium oxalate crystals. The glomeruli were normal, as were the ascending loops of Henle and second convoluted tubules, apart from some dilatation. No mention was made of oxalate deposits elsewhere in the body. Macroscopically the kidneys were pale and swollen, with cut surfaces finely marked with yellow flecks in the natural pattern of the renal tubules (cf. Cases 1 and 2). In further studies (Dunn et al., 1924b) of experimental "oxalate nephritis" they found that on administering oxalates there was an initial oliguria, later followed by polyuria. Albuminuria was a constant finding, associated with an increasing elevation of the blood urea and the passage of pale dilute urine. These features, which cleared up when oxalates were withdrawn, have much in common with those observed in Case 1 .

Case 2.- It is noteworthy that the parents of this boy were first cousins. Unfortunately he was an only child, and it was not possible to investigate other members of his family. His rapid deterioration is a clinical puzzle. Although the constrictive pericarditis may have played a part, it is also possible that the induced diuresis may have promoted the precipitation of calcium oxalate in the renal tubules. In support of this idea, it will be recalled that in Case 1 the two acidotic episodes were preceded by diuresis.

Pathologically the sites of crystal deposition are intriguing. The most commonly reported sites of deposits are in kidney, bone, and myocardium, 
whilst other sites include thymus, testis, and pancreas (Neustein, Stevenson, and Krainer, 1955), thyroid and adrenals (Burke et al., 1955). More recently crystals have been reported in the pulmonary alveoli and lymph nodes (Godwin et al., 1958), whilst Scowen et al. (1959) described them in many of these sites and also in arteries and arterioles throughout the body ; also sparsely in the anterior pituitary, tonsil, and ciliary body of the eye. Perhaps the most interesting sites in Case 2 are at the osteochondral junction of bone and in a partly calcified lymph gland, for here a high concentration of calcium ions would be expected and would be available to combine with oxalic acid. The presence of deposits in arterial and arteriolar walls and in myocardium remains inexplicable, though Scowen et al. (1959) have suggested an association with smooth muscle metabolism.

Various authors have reported the calcium and oxalate contents of kidneys in affected cases, but many of these values have been expressed as percentages of wet weight of kidney and the method of determination has not been described. The values in Case 2 are of the same order as those reported by Scowen et al. (1959), using the same method.

The relationship to calcium metabolism is uncertain, but, in the limited investigations carried out, both cases had a reduced calcium excretion, while the serum calcium in Case 2 declined terminally.

Possitble Aetiology.-The work of Scowen's group (Scowen, Crawhall, and Watts, 1958) and others suggests that the excretion of excessive amounts of oxalate in primary hyperoxaluria is due to abnormal endogenous formation, rather than to any excessive absorption from the gastrointestinal tract or a low renal threshold for oxalate. The exact biochemical lesion responsible is unknown, however. Oxalic acid has no known role in mammalian intermediary metabolism, and indeed some experiments suggest that it is relatively inert (vide infra). In some moulds it is formed from acetate with glycolate and glyoxalate as intermediaries (Nord and Vitucci, 1947). Weinhouse and Friedmann (1951), however, using $\mathrm{C}^{14}$-labelled compounds, failed to demonstrate such a pathway in live rats, although glyoxalate was certainly converted to oxalate. Moreover, oxalic acid seemed relatively inert as it was converted neither to glyoxalate nor to $\mathrm{CO}_{2}$, and $80 \%$ of the administered dose could be recovered from the urine and tissues. The administration of ethylene glycol, glyoxal, glycolic acid, purines, and creatinine has been reported to increase oxalate excretion in animals (Jeghers and Murphy, 1945), but it has been impossible to demonstrate oxalate synthesis by mammalian tissue slices from most of these substrates, nor was oxalate destroyed by such slices (Barber and Gallimore, 1940). In rat liver, however, the reaction glycine $\longrightarrow$ glyoxalate $\rightarrow$ formate has been demonstrated by Nakada, Friedmann, and Weinhouse (1955), and Nakada and Weinhouse (1953) have shown that when glyoxalate is present in excess it is converted to oxalate, thus providing a possible pathway for oxalate formation from glycine.

Experiments by Scowen's group (Archer et al., 1958a) have, in fact, suggested that oxalate arises from glycine in man ; for the oxalate excretion of patients with primary hyperoxaluria was reduced by lowering the free glycine metabolic pool by giving sodium benzoate. In a further study (Scowen et al., 1958) the administration of glycine1-13C led to considerable incorporation of the isotope into the urinary oxalate.

Yet another possible source of glyoxalate is from acetate via the "glyoxalate cycle" recently described by Kornberg and Krebs (1957). But this has so far only been established in microorganisms.

The evidence at present favours glyoxalate as an immediate precursor of oxalate, this in turn arising from glycine or, less likely, from acetate. On this scheme excessive glyoxalate could arise as a direct result of excessive formation from glycine (or acetate), or alternatively by blocking of the reaction glyoxalate $\rightarrow$ formate, or one of the normal metabolic pathways of glycine so that more glycine was metabolized along the glyoxalate-formate pathway (see diagram below). Since the condition appears to be hereditary such a metabolic block could be a manifestation of a genetically transmitted enzyme deficiency, as occurs in the "inborn errors of metabolism" (Garrod, 1923). Further studies are obviously needed, but unfortunately the biochemical investigation of this condition is difficult : first, the disease is rare ; secondly, there is no satisfactory method to estimate blood oxalate levels (Barrett, 1943) ; and, thirdly, many cases are in advanced renal failure when diagnosed, so that studies of their oxalate excretion must be interpreted cautiously.

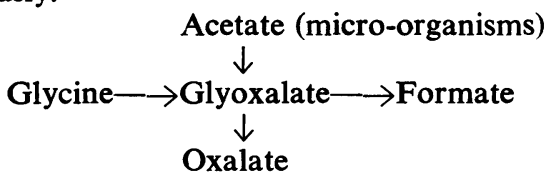


Crystal Formation.-The condition poses other problems. The sites of crystal deposition have already been discussed, but why do they form rosette patterns in the body quite different from the form taken on crystallization out of simple solution? Their shape, which is similar to that found in some plants (Glynn, 1940), may indeed be due to their precipitation in some sort of organic matrix as suggested by their staining reactions (vide supra). Indeed, it has been suggested (Keyser, 1938) that calcium oxalate crystals agglutinate in an organic framework of colloid to form calculi. How rapidly do the crystals form and what factors initiate their formation? Crystals are found within 24 hours in cases of ethylene glycol poisoning, suggesting a rapid formation, but on the other hand nephrocalcinosis has been observed some time before death. In fact, the speed of deposition of crystals and the extent to which they impair renal function may vary, and crystals may be precipitated in definite periodic attacks, during which the patient may succumb or survive. Several of the cases reported give a history of "attacks" apart from those due to calculi, and Case 1 survived his first attack. It is likely that oxalate excretion is increased at such times with the precipitation of calcium oxalate in the renal tubules. In Case 1 the massive deposition of oxalate crystals in the renal tubules caused death, but in other cases calculi rather than crystals may form, leading to recurrent calculous pyelonephritis. Death from renal damage may be due to this rather than to damage from the crystals themselves, as suggested by Scowen et al. (1959) in their cases. The cause of these episodes of crystal deposition remains uncertain. Dehydration may be a factor, and Black (1945) has suggested, on the basis of the finding of oxalate crystals in the urine, that episodes of such crystalluria due to dehydration were responsible for many cases of renal colic and haematuria among British troops in India in the last war.

\section{Summary}

Two fatal cases of oxalosis are presented: the first was in a boy of 14 weeks who presented with severe dehydration and acidosis and had crystalline deposits of calcium oxalate in the renal tubules and brain. Attention is drawn to this method of presentation, as it seems possible that if it is borne in mind further cases may be diagnosed.

The second case was in a boy of 14 years who had bilateral renal calculi and rapid renal failure.
Here crystals were found in kidneys, bone, myocardium, thyroid, testis, and calcified lymph node.

The pathogenesis of the condition remains uncertain, but the evidence so far strongly suggests that an inborn error of metabolism leads to excessive oxalate formation.

It is a pleasure to thank Professor Dorothy Russell for her constant encouragement and guidance, Dr. R. H. Dobbs and Dr. Wallace Brigden for permission to publish the clinical details of cases under their care, and Dr. R. W. E. Watts, of St. Bartholomew's Hospital, for advice in the chemical estimations; also Mr. J. King for the photomicrographs.

\section{REFERENCES}

Andrews, J. C., and Viser, E. T. (1951). Food Res., 16, 306

Aponte, G. E., and Fetter, T. R.(1954). Amer. J. clin. Path., 24, 1363. Archer, H. E., Dormer, A. E., Scowen, E. F., and Watts, R. W. E. (1957a). Lancet, 2,320.

- (1957b). Clin. Sci., 16, 405.

- (1958b). Ann. hum. Genet., 22, 373

Baldwin, H. (1900). J. exp. Med., 5, 27.

Barber, H. H., and Gallimore, E. J. (1940). Biochem. J., 34, 144. Barrett, J. F. B. (1942). Lancet, $2,574$.

(1943). Biochem. J., 37, 254.

Begbie, J. (1849). Monthly J. med. Sci., $9,943$.

Bird, G. (1842). Lond. med. Gaz., 30, 637 and 749.

Black, J. M. (1945). Brit. med. J., 1, 590.

Burke, E. C., Baggenstoss, A. H., Owen, C. A., Jr., Power, M. H., and Lohr, O. W. (1955). Pediatrics, 15, 383 .

Butler, A. M., Wilson, J. L., and Farber, S. (1936). J. Pediat., 8, 489.

Donné (1839). C.R. Acad. Sci. (Paris), 8, 805.

Dunn, H. G. (1955). Amer. J. Dis. Child., 90, 58.

Dunn, J. S., Haworth, A., and Jones, N. A. (1924a). J. Path. Bact., 27, 299.

(1924b). Ibid., 27, 377.

Edwards, D. L. (1957). A.M.A. Arch. Path., 64, 546.

Garrod, A. E. (1923). Inborn Errors of Metabolism, 2nd ed. Oxford University Press, London.

Glynn, L. E. (1940). J. Path. Bact., 51, 445.

Godwin, J. T., Fowler, M. J., Dempsey, E. F., and Henneman, P. H. (1958). New Engl. J. Med., 249, $10 ; 9$.

Gram, H. C. (1932). Acta med. scand., 78, 268.

Hodgkinson, A. (1958). Proc. roy. Soc. Med., 51, 970.

Jeghers, H., and Murphy, R. (1945). New Engl. J. Med., 233, 208 and 238 .

Katzuni, E., and Sandbank, U. (1959). Arch. Dis. Childh., 34, 60.

Keyser, L. D. (1938). Bull. N.Y. Acad. Med., 14, 76.

Kornberg, H. L., and Krebs, H. A. (1957). Nature (Lond.), 179, 988.

Laas, E. (1941). Frankfurt. Z. Path., 55, 265.

Lamden, and Chrystowski (1953). Fed. Proc., 12, 420.

Loeper, M. (1933). Nutrition (Paris), 3, 1.

Lepoutre (1925). J. Urol. méd. chir., 20, 424.

Lightwood, R. (1935). Arch. Dis. Childh., 10, 205.

Lund, T., and Reske-Nielsen, E. (1956). Acta path. microbiol. scand.,

38, 353.
Mulloy, M., and Knutti, R. E. (1951). J. Pediat., 39, 251 and 253.

Myers, N. A. A. (1957). Arch. Dis. Childh., 32, 48.

Nakada, H. I., and Weinhouse, S. (1953). Arch. Biochem. Biophys. 42, 257 .

Friedmann, B., and Weinhouse, S. (1955). J. biol. Chem., 216 , 583.

Neustein, H. B., Stevenson, S. S., and Krainer, L. (1S55). J. Pediat., 47, 624 .

Newns, G. H., and Black, J. A. (1953). Gt Ormond St. J., No. 5, p. 40. Nord, F. F., and Vitucci, J. C. (1947). Arch. Biochem., 14, 229.

Osler, W. (1935). The Principles and Practice of Medicine, 12th ed. p. 689, ed. rev. McCrae, T. Appleton-Century Co., New York and London.

Pons, C. A., and Custer, R. P. (1946). Amer. J. med. Sci., 211, 544 Pons, C. A., and Custer, R. P. (1946. (1954). Amer. J. Path., 30, 545. Rodillon, J. (1933). Nutrition (Paris), 3, 43.

Scowen, E. F., Crawhall, J. C., and Watts, R. W. E. (1958), Lancet, 2. 300 .

'Stansfeld, A. G., and Watts, R. W. E. (1959). J. Path. Bact. 77,195 .

Weinhouse, S., and Friedmann, B. (1951). J. biol. Chem., 191, 707. Ying Chou, L., and Donohue, W. L. (1952). Pediatrics, 10, 660.

Zollinger, H. U., and Rosenmund, H. (1952). Schweiz. med. Wschr. 82,1261 . 